\title{
Annotated bibliography of three-mode factor analysis
}

\section{Pieter M. Kroonenberg}

Published and unpublished theoretical and applied papers on three-mode principal component analysis and factor analysis have been annotated. In addition, the applications have been elassified according to subject matter, data type, language and the theoretical papers have been elassified according to problem, model, method or computer program treated.

\section{Contents}

1. Introduction

2. Three-mode analysis in perspective

3. Theoretical papers

4. Computer programs

5. Classification of applications

5.1 Subject matter

5.2 Data types

5.3 Languages (other than English)

6. Glossary

7. Annotated bibliography

8. Late additions

\section{Introduction}

This bibliography contains papers which can be roughly divided into two eategories.

The first category consists of theoretical papers dealing with the three-mode principal component (or factor) model or with closely related models; the second consists of applications of three-mode analysis. For simplicity the terms 'three-mode analysis' and 'three-mode model' will be used to refer to three-mode principal component analysis (model) or three-mode factor analysis (model), or both.

An attempt has been made to include all theoretical papers dealing explicitly with three-mode analysis, and to include those papers dealing with related methods which have some direct bearing on three-mode analysis. In general, the most influential paper of a number of roughly equivalent ones was chosen. Explicitly excluded are papers dealing with the analysis of covariance structures (Jöreskog c.s. and Bentler c.s.) which do not refer to core matrices. Some methods proposed within that field resemble the ones cited here quite closely (see, for example, Bentler \& Lee, 1978). An extensive effort was made to include all available applications of three-mode analysis, whether published or not. No applications of related techniques such as INDSCAL, CANDECOMP, IDIOSCAL and PARAFAC were included. In particular, the INDSCAL literature is quite large, very much imbedded in the general multidimensional scaling literature, and it deserves a separate bibliography. 
At the end of an entry an extra date is sometimes included in square brackets. This indicates that references to earlier unpublished versions of the same manuscript were encountered.

The papers were selected via computer research of the Social Sciences Citation Index (SSCI, 1972-1980), Psychological Abstracts (1967-1980), Sociological Abstracts (1963-1980), Science Citation Index (1978-1980), Dissertation Abstracts (1964-1980), and ERIC (1966-1980), and references cited in various papers. Furthermore, an attempt was made to cover the pre-SSCI period as well as possible, but undoubtedly some papers will have been missed. The same is true for unpublished manuscripts. The latter only accidentally have come my way, and any systematic search is obviously impossible. Any additional references are very welcome, especially if accompanied by the document itself. If no annotation has been given, I have not been able to obtain a copy of the particular reference. Copies of such documents would also be very welcome.

\section{Three-mode analysis in perspective}

Tucker $(1963,1964,1966)$ was the first to introduce the three-mode model in the social sciences. Part of the development of this model is also contained in the unpublished thesis of Levin (1963). The model is an example of what is known as multilinear algebra in mathematics, but there are hardly any cross-references (see, however, Kruskal, T1976, T1977). $\dagger$

Tucker $(1966 b)$ contains both methods to solve the three-mode principal component model (Method I and Method II), and a start for the solution of a threemode factor analysis model with one stochastic mode (Method III). The latter model was, be it somewhat tortuously, further developed by F. W. Snyder $(1967,1968)$. A truly factor-analytic model was first proposed by Bloxom (1968), and variants of his model were developed by Bentler \& Lee $(1978,1979)$, who also developed computer programs for the solution of their models. Their approach links three-mode factor analysis to the general theory of linear structural equation models, while, in contrast, Tucker's original approach evolved from and remains within the classical factor analysis framework by treating all modes as fixed rather than stochastic.

In the late 60 s interest in multidimensional scaling (MDS) of three-way data, especially in relation to individual differences, gave rise to the development of models for three-way MDS, like INDSCAL (Carroll \& Chang, 1970), PARAFAC2 (Harshman, 1972 $a, 1976$ ), INDIOSCAL (Carroll \& Chang, 1972), and a number of variants, (e.g. Schönemann, T1972; Schulz, T1975; Schulz \& Pittner, T1978). Tucker (1972a) showed how his three-mode model could be used in three-way MDS by introducing what came to be called three-mode scaling. A summary of these models and their relationships (except for the Schulz' variants) can be found in Carroll \& Wish (1974), while a more complete, but less detailed review is given by Carroll \& Arabie (1980). Another instructive overview including a number of later references is provided by Lohmöller \& Wold (1980).

Algorithms developed in the field of multidimensional scaling and structural equation models have made it possible to make further advances into solving some outstanding problems in the field of three-mode analysis. In particular, the alternating least squares principle (Young et al., T1980), and partial least squares procedures (Wold, T1966; Wold \& Lyttkens, T1960) opened the possibilities for

† References preceded by a 'T" are not contained in the bibliography, but appear at the end of this section. 
obtaining least squares solutions for the model parameters (Kroonenberg \& De Leeuw, 1977, 1978, 1980; Lohmöller \& Wold, 1980), and also allowed the extension of three-mode analysis to other levels of measurement (for an example of a restricted model, see Sands, 1978, Sands \& Young, 1980).

The various models for treating three-way data were initially viewed as a series of more and more specialized models. Possibly inspired by the developments for structural equation models, the three-way models came to be seen as models which could be sequentially tested by increasing or decreasing the number of constraints on the parameters. In fact, Bentler \& Lee $(1978,1979)$ and Lohmöller \& Wold (1980) indicate ways to do this for their restricted models. Especially in multidimensional scaling, minimization of loss functions under constraints using some type of alternating least squares procedure is a field in full development (Bentler \& Weeks, T1978; Bloxom, T1978; Borg \& Lingoes, T1980; Carroll et al., 1980; De Leeuw \& Heiser, T1980). The latter prove a theorem which shows that solving the three-mode principal component model under constraints on the parameters is possible. The approach using constraints seems a more appropriate way to assess the adequacy oi a model compared with a more general or restricted model, than the approaches given by Cohen (1974, 1975), Kroonenberg \& De Leeuw (1977), De Leeuw \& Pruzansky (1978) and MacCallum $(1976 a, b)$, which attempt to rotate the core matrix to a specified target. Just as confirmatory factor analysis has supplanted congruence rotations to specified target matrices, so will rotational assessment of hierarchical three-mode models give way to three-mode analysis under constraints on the model parameters.

Extensions to $N$-mode analysis have been worked out in theory (e.g. Carroll \& Chang, 1970; Harshman, 1970; Carroll \& Wish, 1974), but attempts to implement them have been few and far between (Carroll \& Chang, 1970; Lastovicka, 1981). I assume that this has been partly because of the inherent complexity in programming and interpretation, partly because of the difficulty of generating appropriate data which demand such analyses. It is no problem to conceptualize adequate data, after all Cattell's data box (T1966) has 10 ways, but few investigators either take the trouble to collect such data or really look at what are essentially fourway and higher interactions.

\section{References}

Bentler, P. M. \& Weeks, D. G. (1978) Restricted multidimensional scaling models. Journal of Mathematical Psychology, 17, $138-151$.

Bloxom, B. (1978). Constrained multidimensional scaling in $N$ spaces. Psychometrika, 43, $397-408$.

Borg, I. \& Lingoes, J. C. (1980). A model and algorithm for multidimensional scaling with external constraints on the distances. Psychometrika, 45, $25-38$.

Cattell, R. B. (1966). The data box: Its ordering of total responses in terms of possible relational systems. In R. B. Cattell (ed.), Handbook of Multivariate Experimental Psychology. Chicago, IL: Rand MeNally.

De Leeuw, J. \& Heiser, W. (1980). Multidimensional scaling with restrictions on the configuration. In P.R. Krishnaiah (ed.), Multivariate Analysis-V. Amsterdam/New York: North Holland.

Kruskal, J. B. (1976). More factors than subjects, tests and treatments: An indeterminacy theorem for canonical decomposition and individual differences scaling. Psychometrika, 41, 281-293.

Kruskal, J. B. (1977). Three-way arrays: Rank and uniqueness of trilinear decompositions, with applications to arithmetic complexity and statistics. Linear Algebra and its Applications, 18, $95-138$.

Schönemann, P. H. (1972). An algebraic solution for a class of subjective metrics models. Psychometrika, 37, 441-451.

Schulz, U. (1975). Zu einem Dekompositionsmodell der multidimensionalen Skalierung mit individueller Gewichtung der Dimensionen. Psychologische Beiträge, 17, 167-187. 
Schulz, U. \& Pittner, P. M. (1978). Zur multidimensionalen Skalierung individueller Differenzen. Psychologische Beiträge, 20, 294-315.

Wold, H. (1966). Estimation of principal components and related models by iterative least squares. In P. R. Krishnaiah (ed.), Multivariate Analysis. New York: Academic Press.

Wold, H. \& Lyttkens, E. (eds) (1969). Nonlinear iterative partial least squares (NIPALS) estimation procedure. Bulletin of International Statistical Institute, 43, 2947.

Young, F. W., De Leeuw, J. \& Takane, Y. (1980). Quantifying qualitative data. In E. D. Lantermann \& H. Feger (eds), Similarity and Choice. Vienna, Austria: Hans Huber.

\section{Theoretical papers}

Primarily three-mode analysis

ALS (PLS)

Constrained T3

Covariance structures approach

Exposition of T3

Rotation of core matrix

Scaling of input data

T2-model

T3-model

Three-mode scaling

Unique variances

Weighted model (ALSCOMP3)

Closely related models/methods

CANDECOMP

CANDELINC

INDSCAL

\section{IDIOSCAL}

\section{PARAFAC}

PINDIS

Point-of-view analysis

Review
Kroonenberg \& De Leeuw (1977, 1978, 1980), Lohmöller \& Wold (1980), Sands (1978), Sands \& Young (1980).

Carroll et al. (1980).

Bentler \& Lee (1978, 1979), Bloxom (1968).

Hohn (1979), Levin (1965), Lohmöller (1979a), Van de Geer (1975).

Cohen (1974, 1975), De Leeuw \& Pruzansky (1978), Kroonenberg \& De Leeuw (1977), MacCallum (1974a, $1976 b)$.

Kroonenberg (1981b).

Carroll \& Chang (1972), Israelsson (1969), Jennrich (1972), Kroonenberg \& De Leeuw (1977, 1978, 1980), Tucker (1975).

Bartussek (1973), Jaffrennou (1978), Kroonenberg \& De Leeuw (1980), Levin (1963, 1965), F. W. Snyder \& Tucker (1970), Tucker $(1964,1965$, 1966, 1975).

Tucker (1972a, $b, 1975)$.

F. W. Snyder (1968).

Sands (1978), Sands \& Young (1980).

Carroll \& Chang (1970), Harshman (1970).

Carroll et al. (1980).

Carroll \& Chang (1970), De Leeuw \& Pruzansky (1978), Jaffrennou (1978).

Carroll \& Chang (1970, 1972), De Leeuw \& Pruzansky (1978).

Harshman (1970, 1972a, b, 1976).

Lingoes \& Borg (1978).

Tucker \& Messick (1963).

Carroll \& Arabie (1980), Carroll \& Wish (1974), Law \& Snyder (1979), Lohmöller \& Wold (1980). 
Taxonomy

Three-mode path analysis

Three-mode point-of-view

Three-way unfolding

\section{Vaguely related models}

Double principal component analysis

Extension of 'binary method

of Faverge'

\section{Computer programs}

ALS/PLS

Analysis of Covariance structures approach

Orlik's Summax method

Three-mode scaling

Tucker's (1966) Method I

Tucker's (1966) Method II

Tucker's (1966) Method III
Carroll \& Arabie (1980).

Lohmöller \& Wold (1980).

Tzeng \& Landis (1978).

DeSarbo (1978), DeSarbo \& Carroll $(1979,1981)$.

Bourouche \& Dussaix (1975).

Karnas (1975).

Kroonenberg $(1981 a, c)$, Kroonenberg \& De Leeuw (1980), Lohmöller \& Wold (1980), Sands (1978), Sands \& Young (1980).

Bentler \& Lee (1978, 1979).

Kohler (in preparation).

SOUPAC (1973), Redfield (1978).

Gräser (1977), Kouwer (1967), Lohmöller

(1979b), McCloskey \& Jackson (1979),

Redfield (1978), SOUPAC (1973),

Teufel (1969), Van de Geer (1975),

Walsh (1964), Walsh \& Walsh (1976).

Gruvaeus, Wainer \& Snyder (1971),

Lohmöller (1979b), Redfield (1978),

Van de Geer (1975), Wainer et al. (1973).

Lohmöller (1979b), Redfield (1978), C. W.

Snyder \& Law (1979), C. W. Snyder et al. (1979), SOUPAC (1973), Zenisek (1978).

Belk (1974).

Vavra (1972).

Vavra (1973).

Lastovicka (1981).

Witzke (1975).

Lilly (1965). 


\section{Education}

Achievement concepts

Aviation students

Computer assisted instruction

Educational careers

Media usage

Multiple-cue learning

Novelty

Progress in school subjects

Serial learning

Stressful university situations

Task learning

Task-solving strategies

\section{Evoked potentials; EEGs}

Evoked potentials

Various basic aspects of EEGs

Activity situations and EEGs

Personality factors sensu Eysenck

\section{Geology}

Organic extracts and elements

Cations

\section{Geography}

Changes in land use

Changes in location of manufacturing

Spatial-temporal analysis

\section{Law}

Junvenile delinquents
Knobloch (1972).

F. W. Snyder (1968).

Moonen (1978).

Stoop (1980).

Lohmöller \& Oerter (1979).

Montanelli (1972).

Bernstein \& Wicker (1969).

Hanke et al. (1980), Lohmöller (1978, $1979 a, 1981)$, Lohmöller \& Wold (1980).

Love \& Tucker (1970).

Kjerulff \& Wiggins (1976).

Fruchter (1969), Tucker (1965, 1967), Rowe (1979).

Donchin et al. (1972).

Bartussek (1980).

Bartussek et al. (1972), Bartussek \& Gräser (1980).

Rösler (1972, 1975).

Hohn (1979).

Hohn \& Friberg (1979).

Baerwald (1976).

Cant (1971).

Chojnicki \& Czyż (1976).

Occupational and organizational psychology; business administration

Administrative tasks

Airline reservation agents

Hospital organization

Job classification

Job satisfaction

Organizational behaviour
F. W. Snyder (1968).

Inn et al. (1972).

Lammers (1974), Van de Geer (1974).

Cornelius et al. (1979).

Algera (1980), Zenisek (1980).

Frederiksen (1972), Frederiksen et al. (1972). 
Personality and social psychology

Abstract paintings

Achievement concepts

Anxiousness

Assertiveness

Disjunctive conceptual behaviour

Functional relations

Gift giving

Implicit theories of personality

Life events

Manual expression

Perception of social environment

Person stimuli

Personality trait profiles

Personality traits

Reversible figures

Self-conception

Self-report/peer-report

Social judgement

Social perception

Social structure

Subjective culture

Baltink (1968, 1969), Frey (1973), Litt (1966).

Knobloch (1972).

Levin (1965), Tucker (1965).

Firth \& Snyder (1979), Leah et al. (1979).

C. W. Snyder $(1970,1976)$.

Groves (1978).

Belk (1979).

Van der Kloot \& Kroonenberg (1982), Wiggins \& Blackburn (1976).

Gräser et al. (1981), Redfield \& Stone (1979), Saile (1979).

Gitin (1970).

Triandis (1976, 1977), Triandis et al. (1967, 1975).

Davis \& Grobstein (1966).

Stewart (1971, 1974).

Schmitt et al. (1977).

Gräser (1977).

Tzeng (1977b).

Bentler \& Lee (1978).

Hirshberg (1980).

Imada \& London (1979).

MacCallum (1974b).

Triandis (1973)

\section{Phonetics}

Confusion of consonants

Kroonenberg \& De Leeuw (1980).

\section{Politics}

American

Dutch

German

Swedish

US Senate

Sands (1978), Sands \& Young (1980), Shikiar $(1974 a, b)$.

Kroonenberg $(1981 a, c)$, Kroonenberg \& De Leeuw (1977, 1978, 1980).

Rösler (1979).

Sjöberg (1977).

Wainer et al. (1973).

\section{Psychiatry}

Heart conditions

Walter (1976).

Neuroticism

Leichner (1975).

Schizophrenicity

Mills \& Tucker (1966). 
Psychophysics

Psychomotor learning

Size-weight illusion

Synesthetic thinking

Sound quality

\section{Religion}

Religious attitudes

\section{Semantic differential studies}

Affective meaning systems

Affective and denotative meaning

Cross-cultural

Thesaurus

Self-concept description

Developmental changes

\section{Stimulus scaling}

Adjective similarity

Confusions of consonants

Personality traits

Soft drinks

Sound quality

\section{Miscellaneous psychology}

Adjective similarity

Leisure

Road research

Soft drinks

Word association
Fruchter (1968), Tucker (1965, 1967).

Groves (1978).

Wicker (1966, 1968).

Gabrielsson \& Sjögren (1974/75).

Muthén et al. (1977).

F. W. Snyder \& Wiggins (1970).

Tzeng (1972, 1975, 1977a).

Tzeng \& Landis (1978).

F. W. Snyder (1967).

Hentschel \& Klintman (1974).

Lilly (1965).

MacCallum (1976b), Tucker (1972a).

Kroonenberg \& De Leeuw (1980).

Van der Kloot \& Kroonenberg (1982).

Cooper (1973).

Gabrielsson \& Sjögren (1974/75).

MacCallum (1976b), Tucker (1972a).

London et al. (1977).

C. W. Snyder \& Law (1981).

Cooper (1973).

Rychlak et al. (1979).

\subsection{Data types}

\section{Semantic (or behavioural) differential scales}

Baltink (1968, 1969), Bernstein \& Wicker (1969), Davis \& Grobstein (1966), Frey (1973), Gitin (1970), Hentschel \& Klintman (1974), Imada \& London (1979),

Leichner (1975), Levin (1964, 1965), Litt (1966), MacCallum (1976b), Meijs (1980), Muthén et al. (1977), Redfield \& Stone (1979), F. W. Snyder (1967), F. W. Snyder \& Wiggins (1970), Triandis (1972, 1976), Triandis et al. (1967, 1975), Tzeng (1972, 1975, 1977), Tzeng \& Landis (1978), Wicker (1966, 1968), Wiggins \& Blackburn (1976).

Multitrait multimethod matrices analysed with Tucker (1966) Method III or Bentler \& Lee $(1978,1979)$.

Bentler \& Lee (1978, 1979), Firth \& Snyder (1979), Hoffman \& Tucker (1964), Leah et al. (1979), Schmitt et al. (1977), C. W. Snyder $(1970,1976)$, F. W. Snyder (1967), Tucker $(1965,1966,1967)$. 
Time series data

Baerwald (1976), Bourouche \& Dussaix (1975), Cant (1971), Gräser (1977), Hanke et al. (1980), Inn et al. (1972), Lammers (1974), Lohmöller (1978, 1979a, 1981),

Lohmöller \& Wold (1980), Love \& Tucker (1970), Van de Geer (1974).

\section{Similarity type data}

Cooper (1973), Kroonenberg \& De Leeuw $(1977,1978,1980)$, Kroonenberg \& De Leeuw (1981 $a, c)$, MacCallum (1976b), Rösler (1979), Shikiar $(1974 a, b)$, Tucker $(1972 a)$.

\subsection{Languages (other than English)}

\section{Dutch}

Algera (1980), Baltink (1968, 1969), Kouwer (1967), Kroonenberg \& De Leeuw (1978), Lammers (1974), Meijs (1980), Meuwese (1970), Moonen (1978), Stoop (1980), Van de Geer (1974, 1975), Walter (1976).

French

Jaffrennou (1978), Karnas (1975).

\section{German}

Bartussek (1973, 1980), Bartussek \& Gräser (1980), Bartussek et al. (1972), Frey (1973), Gräser (1977), Hanke et al. (1980), Knobloch (1972), Kohler (in preparation), Leichner (1975), Lohmöller \& Oerter (1979), Lohmöller (1979a, b, 1981), Orlik (1980), Rösler (1972, 1975), Teufel (1969).

\section{Glossary}

Basic terms

Combination-mode $(i j)$

Combination-mode matrix

Core matrix

Element (of a mode)

Extended core matrix
Cartesian product of two (elementary) modes $i$ and $j$; ' $i$ outer loop, $j$ inner loop'; see Tucker (1966, p. 281).

Two-mode matrix with one (elementary) mode (usually columns) and one combination-mode (usually rows).

Three-mode matrix, which contains the relations between the components of the various modes; its size is usually $p \times q \times m$, where $p, q$ and $m$ are the number of components for the first, second and third mode respectively.

Generic term for a variable (subject, condition, etc.) in a mode.

Three-mode core matrix, of which one of the dimensions is equal to the number of elements in that mode; its size is usually $p \times q \times k$, where $k$ is the number of elements in the third mode. 
Frontal plane

Mode (or elementary mode), way

Reduced mode

Three-mode matrix (-array) $p \times q$-slice of an (extended) core matrix.

Collection of indices by which the data can be classified; way and mode are here used as synonyms; for a different usage of the word 'mode' in the same context see Carroll \& Arabie (1980).

Mode of which principal components have been computed.

Collection of numbers which can be classified in three (different) ways, i.e. using three indices; the numbers can thus be arranged in a threedimensional block.

\section{Methods}

Analysis of covariance structures approach

Alternating least squares

Partial least squares

Tucker's (1966) Method I

Tucker's (1966) Method II

Tucker's (1966) Method III

Models

\section{CANDECOMP}

In this method the subject mode is treated stochastically and the analysis is performed on the combination-mode covariance matrix of the other two modes. Solutions can be obtained by maximum likelihood estimation, or generalized least squares procedures. An a priori structure for the component matrix and the core matrix can be specified.

An iterative method to solve large and complex models by breaking up the total number of parameters into a number of groups, each of which can be estimated conditional on the fixed values of the parameters in the other groups.

See Alternating least squares.

Straightforward principal component analysis on each of the three combination-mode matrices, and subsequent combination of the three solutions to form the core matrix.

Straightforward principal component analysis on two combination-mode matrices, combined with a clever juggling to compute an approximate core matrix and the third principal component matrix without resorting to solving the eigenvalueeigenvector problem for the largest mode. Appropriate for data sets with one very large mode, usually individuals.

Method to analyse multitrait-multimethod-like covariance and correlation matrices. Forerunner of the analysis of covariance structures approach.

Carroll \& Chang (1970). T3 with a three-way identity matrix as core matrix, or equivalently INDSCAL with different reduced modes. 
IDIOSCAL

INDSCAL

\section{PARAFAC}

Three-mode scaling

Tucker2-model (T2)

Tucker3-model (T3)

Tucker's common factor model
Carroll \& Chang (1972). As T2, but the two reduced modes are equal, and thus the extended core matrix is symmetric in its frontal planes. Allows for both idiosyncratic rotations of axes in the common stimulus space, and individually different weighting of these axes. Component matrices are not necessarily orthogonal.

Carroll \& Chang (1970). As IDIOSCAL, but with the additional restriction that the frontal planes are diagonal, i.e. no idiosyncratic rotations are allowed. The model can also be interpreted to have three reduced modes of equal numbers of components, and a three-mode identity core matrix.

Harshman (1970, 1972a, $b, 1976)$. Parallel profiles factor analysis. PARAFACl is equal to CANDECOMP. PARAFAC2 is similar to IDIOSCAL, but it specifies a common weighting of the axes of the simulus space. However, idiosyncratic rotations of these axes are allowed,

Tucker $(1972 a)$. As the Tucker3 model, but two of three reduced modes are equal. Core matrix has symmetric frontal planes.

Israelsson (1969). Model specifies two unequal reduced modes with an unrestricted extended core matrix.

Tucker (1966). Three unequal reduced modes with an unrestricted core matrix.

Tucker (1966). As T3, but unique variances are specified for the combination-mode covariance matrix.

\section{Annotated bibiography}

Algera, J. A. (1980). Kenmerken van werk. De constructie van een instrument voor het meten van taakkenmerken die van invloed zijn op motivatie, satisfactie en prestaties van taakuitvoerenden. Doctoral thesis. Leiden, The Netherlands.

As part of a larger study T3 (as implemented by Kroonenberg \& De Leeuw, 1980) was performed on 25 jobs in a steel factory, 24 tasks and 10 judges to check whether the judges agreed on the relationships between jobs and tasks. No numerical details given.

Baerwald, T. J. (1976). The emergence of a new "downtown". The Geographical Review, 68, 308-318.

A geographical application of T3 to changes in land use over time with land use classes, time periods and districts as modes. No numerical results presented.

Baltink, G. J. H. (1968). Differentieel-psychologisch onderzoek naar de beoordeling van abstrakte schilderijen met behulp van driemodale faktoranalyse. Unpublished masters thesis, Institute for General Psychology, University of Groningen, The Netherlands (see Baltink, 1969).

Baltink, G. J. H. (1969). Driemodale faktoranalyse in een differentieel-psychologisch onderzoek naar de beoordeling van abstracte schildrijen. Nederlands Tijdschrift voor de Psychologie, 24, 529540. 
T3 and its possible rotations are discussed at a conceptual level. The model is illustrated with an analysis of 15 abstract (non-figurative) paintings, scored on 10 bipolar (semantic) scales by 34 subjects. The relation between neuroticism and extraversion (measured independently), and the resulting factors were analysed using the core matrix.

Bartussek, D. (1973). Zur Interpretation der Kernmatrix in der dreimodalen Faktorenanalyse von L. R. Tucker. Psychologische Beiträge, 15, 169-184.

After a rather clear exposition of T3, generalizing from PCA on two-mode matrices, B. proposes to scale the component matrices such that the components have lengths equal to the corresponding eigenvalues. These eigenvalues are themselves adjusted by division through the total number of elements in the other two modes. The reciprocal scaling is performed for the core matrix elements. These elements become in this way independent of the size of the sum of squares of the components and may therefore be interpreted as 'classical' factor scores. In the same sense the elements of the components correspond to 'classical' factor loadings rather than being just elements of orthogonal eigenvectors. Standardization of the raw data and interpretation of T3 results by comparing them with external variables are discussed as well.

Bartussek, D. (1980). Die dreimodale Faktorenanalyse als Methode zur Bestimmung von EEG-Frequenzbändern. In S. Kubicki, W. M. Herrmann \& G. Laudahn (eds), Faktorenanalyse und Variablenbildung aus dem Elektro-enzephalogramm, pp. 15-26. Stuttgart: Gustav Fischer Verlag.

T3 is outlined, its relation to Cattell's (T1966) data box is indicated, and the interpretation of the core matrix for EEG data is discussed. Also included is a discussion of the subject and situation selection, the norming of the EEG

frequency spectra to be calculated, the standardization of the spectrum values and the choice of a time basis for the frequency analysis.

Bartussek, D. \& Gräser, H. (1980). Ergebnisse dreimodaler Faktorenanalysen von EEG-Frequenzspektren. In S. Kubicki, W. M. Herrman \& G. Laudahn (eds), Faktorenanlyse und Variablenbildung aus dem Electro-enzephalogramm, pp. 79-87. Stuttgart: Gustav Fischer Verlag. [1978].

The results of two unpublished studies are reported. Of 40 students 30 values of the frequency spectrum for six activity situations were measured in two ways. T3 was performed on data $(40 \times 30 \times 12)$ standardized per spectral value over all student/situation combinations. Frequencies and situations were varimaxed. Special attention was paid to the interpretation of the core matrix and the effects of standardization. In the other study three values were collected from 20 subjects in 24 situations. Data standardized as above. Frequencies were varimaxed; the situations and subjects were obliquely rotated. Again detailed attention to the core matrix.

Bartussek, D., Pawlik, K., \& Rhenius, D. (1972). Eine Dimensionsanalyse des digital frequenzanalysierten EEG und sein Zusammenhang mit Persönlichkeitsvariablen. Paper presented at the 13th meeting of experimental psychologists, Graz, Austria.

Results reported in Bartussek \& Gräser (1980).

Belk, R. W. (1974). An exploratory assessment of situational effects in buyer behaviour. Journal of Marketing Research, 11, 156-163.

The variance in selected purchase decisions was explored as function of consumption and purchase context. T3 was used for data from 100 subjects in 10 situations with 10 snack products, and in 9 situations with 11 meat products. Solutions were obtained via Tucker's Method III. Both situation and product 
spaces were varimax rotated. The same data were also analysed with a three-way mixed effects analysis of variance model.

Belk, R. W. (1979). Gift-giving behavior. In J. N. Sheth (ed.), Research in Marketing, vol. 2, pp. 95-126. Greenwich, CT: JAI Press.

As part of a larger study 12 characteristics in each of 15 gift-giving situations were rated by 219 respondents. The components were varimax rotated, and the two person components were analysed using the core matrix. One component matrix and the core matrix are presented in detail.

Bentler, P. M. \& Lee, S Y. (1978). Statistical aspects of three-mode factor analysis model. Psychometrika, 43, 343-352.

A special case of Bloxom's version (1968) of T3 is developed statistically. A distinction is made between fixed and random modes. Parameter matrices are associated with the fixed modes, while no parameters are associated with the mode representing random observation vectors. Estimation by a weighted least squares method based upon Gauss-Newton. Example based upon self-report and peerreport measures (see also Bentler \& Lee, 1979).

Bentler, P. M. \& Lee, S. Y. (1979). A statistical development of three-mode factor analysis. British Journal of Mathematical and Statistical Psychology, 32, 87-104.

B \& L consider a factor analytic random vector version of T3. The parameters of the model are associated with two fixed modes and the covariance matrix of the random vectors. Their approach brings three-mode FA in the realm of structural equation models. Their model does not treat all three modes symmetrically as Tucker (1966) and Kroonenberg \& De Leeuw (1980) do. With B \& L's model a confirmatory approach to T3 is possible, and standard errors and a goodness-of-fit statistic become available. B \& L's model has some similarity to the treatment of T3 by Tucker (1966) through his Method III. The model is illustrated by a multitrait-multimethod matrix example.

Bernstein, A. L. \& Wicker, F. W. (1969). A three-mode factor analysis of the concept of novelty. Psychonomic Science, 14, 291-292.

A rather simplistic inquiry into the concept of 'novelty' using the unsealed scores of 30 students on an 18 item semantic differential type scale with 10 realistic and unrealistic animals. T3 on cross-products. No serious interpretation.

Bloxom, B. (1968). A note on invariance in three-mode factor analysis. Psychometrika, 33, 347-350.

B. proposes a 'true' factor analysis variant of T3, where the derived factor scores, the scores of the subjects on the combination variables and the errors are random variables rather than matrices of parameters for a finite number of individuals (see also Bentler \& Lee, 1978, 1979). Conditions for the invariance across subpopulations for the factor pattern matrices, the core matrix and the residual covariance matrix are discussed.

Bouroche, J. M. \& Dussaix, A. M. (1975). Several alternatives for three-way data analysis. Metra, 14, $299-319$.

A method called 'Double PCA' is proposed for the analysis of three-way data, say subjects $\times$ variables $\times$ time. First PCA is performed on the variables $\times$ time matrix averaged over subjects to assess general trends. Then for each time PCA is performed over the subjects $x$ variables matrix centred at each variable. Finally four different procedures are discussed to obtain a 'best' common subject-space for all time points. Plots showing the 'trajectory' of each subject in the common space are given. Illustrated with a study of the French car market. 
Cant, R. G. (1971). Changes in the location of manufacturing in New Zealand 1957 1968: An application of three-mode factor analysis. New Zealand Geographer, 27, $38-55$.

The data of 23 employment districts with 26 industries and industrial indicators over 11 years were analysed with T3. A conceptual discussion of T3 is included as well. Although the component matrices were relatively clear, the $7 \times 9 \times 2$ core matrix proved to be too complex for easy interpretation.

Carroll, J. D. \& Arabie, P. (1980). Multidimensional scaling. Annual Review of Psychology, 31, 607-649.

C. \& A. present a taxonomy of the field of multidimensional scaling. Virtually all proposed scaling models are placed in the taxonomy, including T2 and T3 and related three-way models (ef. pp. 630 636).

Carroll, J. D. \& Chang, J. J. (1970). Analysis of individual differences in multidimensional sealing via an $N$-way generalization of "Eckart-Young" decomposition. Psychometrika, 35, 283-319.

A special, restricted variant of T2 - the weighted Euclidian distance model, called INDSCAL - is presented within the context of multidimensional scaling. The method to estimate the parameters proceeds via the minimization of a loss function. It is illustrated with the Miller \& Nicely data and Wish's data on the perception of nations.

Carroll, J. D. \& Chang, J. J. (1972). IDIOSCAL: A generalization of INDSCAL allowing IDIOsyncratic reference systems as well as an analytic approximation to INDSCAL. Paper presented at the Spring Meeting of the Psychometric Society, Princeton, New Jersey, 30-31 March.

Presentation of a generalization of INDSCAL allowing each individual to rotate the common stimulus space orthogonally. Methods for an analytic approximation to INDSCAL are proposed, as well as further restrictions with no individual differences except for scale factors. Some approximate ' $F$-tests' for comparing the models described are discussed.

Carroll, J. D., Pruzansky, S. \& Kruskal, J. B. (1980). CANDELINC: A general approach to multidimensional analysis of many-way arrays with linear constraints on parameters. Psychometrika, 45, 3-24.

Some general multilinear models are introduced, and procedures are described to treat data consisting of a many-way array. A very general theorem is proven which says among other things that a least squares solution for the linearly constrained multi-mode analysis model can be found by finding a least squares solution for the reduced model (e.g. those of Sands \& Young, 1980; Kroonenberg \& De Leeuw, 1980; Lohmöller \& Wold, 1980). The main discussion is on various approaches to constrained multidimensional scaling.

Carroll, J. D. \& Wish, M. (1974). Models and methods for three-way multidimensional scaling. In D. H. Krantz et al. (eds), Contemporary Developments in Mathematical Psychology, vol. II, pp. 57-105. San Francisco: W. H. Freeman.

C. \& W. present primarily the INDSCAL model, but also treat in some detail the differences and similarities of IDIOSCAL, PARAFAC2, three-mode scaling, and INDSCAL. Probably the clearest statement of the relationships between these models.

Chojnicki, Z. \& Czyż, T. (1976). Some problems in the application of factor analysis in geography. Geographical Analysis, 8, 416-427.

Presents a general discussion of factor analysis, and eites possible advantages of T3 for spatial-temporal analysis of geographical data. 
Cohen, H. S. (1974). Three-mode rotation to approximate INDSCAL structure (TRIAS). Paper presented to the Psychometric Society Meeting, Palo Alto, CA.

It is proposed to rotate the extended core matrix from a three-mode scaling solution to approximate INDSCAL structure by using INDSCAL itself on the core matrix, and using the full rank 'object' space as transformation matrix for the real object space. Illustrated with subjects' judgements of switching network events.

Cohen, H. S. (1975). Further thoughts on three-mode rotation to INDSCAL structure, with jackknifed confidence regions for points. Paper presented at USJapan Seminar on Theory, Methods and Applications of Multidimensional Scaling and Related Techniques, La Jolla, CA.

Cooper, L. G. (1973). A multivariate investigation of preferences. Multivariate Behavioural Research, 8, 253-272.

Three-mode scaling is used to analyse and compare the scalar products derived from preference and similarity judgements of 52 subjects. The stimuli were American soft drinks. The core matrices are heuristically used to form 'homogeneous' groups in the subject space. The method is, however, not necessarily transferable to other data.

Cornelius III, E. T., Hakel, M. D. \& Sackett, P. R. (1979). A methodological approach to job classification for performance appraisal purposes. Personnel Psychology, 32, 283-297.

Data from a job inventory containing 153 worker-oriented elements were obtained from 2023 incumbents across 18 jobs and 5 levels of responsibility (ranks) in the US Coast Guard. The mean values of the 153 scores of the respondents for each of the job $x$ responsibility combinations were used for a T3 analysis. No scaling of the data; varimax rotations. The elements of the core matrix were interpreted in relation to the average value of each plane. The relatively clear solution was used to decide on the number and contents of forms necessary for evaluating personnel in the US Coast Guard.

Davis, E. E. \& Grobstein, N. N. (1966). Multimode factor analysis of interpersonal perceptions. Technical Report No. 36, Department of Psychology, University of Illinois.

Eighty-eight white/black, male/female students scored 28 complex person stimuli designated mainly in terms of race, sex, religion and occupation on 15 behavioural differential scales. The T3 solution was varimaxed for scales and students. The stimuli components were rotated to agree closely with the discriminant functions, emerging from an analysis on the components. The counter-rotated core matrix was interpreted but did not provide obvious subject component interpretations.

De Leeuw, J. \& Pruzansky, S. (1978). A new computational method to fit the weighted Euclidean distance model. Psychometrika, 43, 479-490.

Deals mainly with fitting the weighted Euclidean distance model, (INDSCAL), but also includes a discussion of three-mode scaling, and ways to rotate the results of that procedure to INDSCAL form (see also MacCallum, 1976b; Cohen, 1974, 1975).

DeSarbo, W. S. (1978). Three-way unfolding and situational dependence in consumer preference analysis. Unpublished doctoral thesis, University of Pennsylvania, Philadelphia, PA (see DeSarbo \& Carroll, 1981).

DeSarbo, W. S. \& Carroll, J. D. (1979). Three-way unfolding. Unpublished working paper, Bell Laboratories, Murray Hill, NJ.

DeSarbo, W. S. \& Carroll, J. D. (1981). Three-way unfolding and situational dependence in consumer preference analysis. Unpublished manuscript, Bell Laboratories, Murray Hill, NJ. 
A metric multidimensional scaling model is developed to accommodate the analysis of three-mode dominance and non-symmetric proximity data. The results for Green \& Rao's breakfast food data are compared with a T3 analysis on these data. No T3 details presented, see however DeSarbo \& Carroll, 1979 (6 situations, 15 food items, 42 respondents).

Donchin, E., Gerbrandt, L. A., Leifer, L. \& Tucker, L. R. (1972). Is the contingent negative variation contingent on a motor response? Psychophysiology, 9, 178-188.

T3 on evoked potential data (7 subjects, 4 conditions, 125 time segments). Results are only partially presented.

Firth, P. M. \& Snyder Jr, C. W. (1979). Three-mode factor analysis of self-reported difficulty in assertiveness. Australian Journal of Psychology, 31, 125-135.

Difficulty in Assertiveness Inventory (Leah et al., 1979). Tucker's Method III (1966) with image factor analysis is used. Replication of Leah's results on students and hospital workers. Referent and response class factors similar, individual differences and core matrix far less so.

Frederiksen, N. (1972). Towards a taxonomy of situations. American Psychologist, 27, 114-123.

F. cites in some detail T3 research of Levin (1965), Tucker (1964) and Frederiksen et al. (1972).

Frederiksen, N., Jensen, O. \& Beaton, A. E. (1972). Prediction of Organizational Behaviour. Elmsford, NY: Pergamon Press.

As part of a project to study the performance of managers in various work situations, the performance of 118 subjects was scored on 11 composite performance variables for each of 37 'in-basket' items. Although an in-depth discussion is given of the substantive results (after equimax rotations to simple structure of the factor matrices), the methodological information is rather scanty.

Frey, C. (1973). Profilskalierung von Kunstzeichnungen in Abhängigkeit von Persönlichkeitseigenschaften der Zeichner sowie der Beurteiler. Unpublished masters thesis, University of Hamburg.

Fruchter, B. (1969). A comparison of two-mode and three-mode factor analysis of psychomotor learning performance. In H. R. Wÿngaarden (Pres.), Proceedings of the XVIth International Congress of Applied Psychology, pp. 330-354. Amsterdam:

Swets \& Zeitlinger.

Gabrielsson, A. \& Sjögren, H. (1974, 1975). Adjective ratings and dimension analysis of perceived sound quality of hearing aids I \& II (Report TA No. 75 \& 77). Stockholm: Karolinska Institute, Technical Audiology.

In the first report, 6 programme sections reproduced via 5 sound reproducing systems (hearing aids) were scored on 62 10-point adjective scales with respect to their sound quality (second report: $6 \times 8 \times 40$ ). In both studies T3 was applied with various scalings and rotations, and the resulting factor spaces were in many respects very similar to those in other factor analyses, but not always so. The interpretation of the core matrices was found to be too difficult. T3 was abandoned in favour of INDSCAL.

Gitin, S. R. (1970). A dimensional analysis of manual expression. Journal of Personality and Social Psychology, 15, 271-277. Also unpublished masters thesis, University of Illinois, 1968.

T3 was performed to investigate 78 subjects' ratings of 36 photographs of manual expressions on 40 semantic-differential-type scales. The expression on scale configurations were varimax rotated, but the core matrix ( $=1$ core plane) is given for the unrotated components. It shows a nice 'simple' (diagonal) structure. 
Gräser, H. (1977). Spontane Reversionsprozesse in der Figuralwahrnehmung. Eine Untersuchung reversibler Figuren mit der Dreimodalen Faktorenanalyse (doctoral thesis). Trier, FRG: author.

The reversion rate of 46 reversible figures for 133 subjects was determined at 15 points in time. T3 as described by Bartussek (1973) was used; all factor matrices were rotated by various methods. Two different standardizations of the data were used; the merits of both are discussed. Reification with external criteria. Extended core matrices were derived by premultiplying the core matrix with component matrices. Interpretation of change factors in T3 is discussed. Includes an Appendix with a program description for T3.

Gräser, H., Esser, H. \& Saile, H. (1981). Einschätzung von Lebensereignissen und ihren Auswirkungen. In S. H. Filipp (ed.), Kritische Lebensereignisse und ihre Bewältigung, pp. 104-122. München: Urban \& Schwarzenberg.

In one of two reported studies on the perception of life events 80 subjects scored 20 life events on 18 sentiments and characteristics. The 18 scales were standardized over subjects and events. Events and scales were varimaxed, and the subjects were obliquely rotated. The core matrix, multiple regression and discriminant analysis on external variables were used to aid the interpretation of the subjects.

Groves, C. L. (1978). Individual difference modelling of simple functional relations: Examples using three-mode factor analysis. Unpublished doctoral thesis, University of Illinois. (Dissertation Abstracts International, 1978, 39 (5-B), $2475-$ 2476).

Simulated fallible data were used to examine the influence of several types of error on the ability of three-mode factor analysis to recover both the stimulus differences in simple functional relations data and the individual differences. Experimental data pertaining to the size-weight illusion were examined.

Gruvaeus, G., Wainer, H., \& Snyder, F. (1971). TREMOD: A 360/75 FORTRAN program for three mode factor analysis. Behavioral Science, 16, 421-422.

Gruvaeus, G., Wainer, H., \& Zill, N. (1971). Mixed modal matrices as aids to interpretation in 3-mode factor analysis. Paper presented at Psychometric Society Meeting, St Louis, MO, April.

Results are partially presented in Wainer et al. (1973).

Hanke, B., Lohmöller, J. B. \& Mandl, H. (1980). Schülerbeurteilung in der Grundschule: Ergebnisse der Augsburger Längsschnittuntersuchung. München: Oldenbourg Verlag.

In the Augsburg longitudinal study about 2500 primary school children were tested for four years. Chapter 6 reports four three-mode studies based on correlation matrices ( 8 school subjects, 6 occasions; 8 rating scales with teacher judgements, 4 occasions; 8 primary mental abilities, 3 occasions; 8 sociometric tests, 3 occasions). The variable modes are varimax rotated. Target rotations to orthogonal polynomials, symmetric rotation of core matrices. Results are interpreted in terms of stability, transformation and continuity (see also Lohmöller, 1981).

Harshman, R. A. (1970). Foundations of the PARAFAC procedure: Models and conditions for an "explanatory" multi-mode factor analysis. UCLA Working Papers in Phonetics, 16, 1-84. (Reprinted by Xerox University Microfilms, Ann Arbor, MI; order no. 10,085.)

Proposes the same model, CANDECOMP, as Carroll \& Chang (1970).

Harshman, R. A. (1972a). PARAFAC2: Mathematical and technical notes. UCLA Working Papers in Phonetics, 22, 31-44. (Reprinted by Xerox University Microfilms, Ann Arbor, MI; order no, 10,085.) 
A model for the analysis of scalar products which allows for common oblique axis projections of the stimuli and individual differences in weights or saliences. The model is a special case of T2. Some uniqueness properties are discussed as well as the relations with INDSCAL and IDIOSCAL.

Harshman, R. A. (1972b). Determination and proof of minimum uniqueness conditions for PARAFAC1. UCLA Working Papers in Phonetics, 22, 111-117. (Reprinted by Xerox University Microfilms, Ann Arbor, MI; order no. 10,085.)

Some minimal conditions for uniqueness of factors in the PARAFAC1-model, which is a special case of T2, are presented and proven (see, however, Carroll \& Wish, 1974, and Carroll \& Arabie, 1980).

Harshman, R. A. (1976). PARAFAC: Methods of three-way factor analysis and multidimensional scaling according to the principle of proportional profiles. Unpublished doctoral thesis, University of California. (Dissertation Abstracts International, 1976, 37, (5-B), 2478 2479). (see Harshman, 1970, 1972a, b).

Hentschel, U. \& Klintman, H. (1974). A 28-variable semantic differential. I. On the factorial identification of content. Psychological Research Bulletin, Lund University, Sweden, 14 (4), 1-27.

T3 was used to assess the structure of semantic differential data of 4 concepts (primarily self-description) scored on 28 bi-polar scales by 209 subjects who did, however, not all score all concepts. Therefore, only very partial results could be obtained.

Hirschberg, N. (1980). Individual differences in social judgment: A multivariate approach. In M. Fishbein (ed.), Progress in Social Psychology. Hillsdale, NJ: Erlbaum.

Contains an overview of multivariate methods to assess individual differences, like MDS, point-of-view analysis, INDSCAL, T3, and preference analyses. One of the examples is a detailed summary of Wiggins \& Blackburn (1976).

Hoffman, E. L. \& Tucker, L. R. (1964). Three-way factor analysis of a multitraitmultimethod matrix. Technical Report, Department of Psychology, University of Illinois, Urbana, IL.

H \& $\mathrm{T}$ reanalyse a multitrait-multimethod (MM) matrix (with comunalities in the diagonal) of Fiske by using the T3 model. Some special formulae were derived to obtain the method and the trait correlation matrices and the core matrix, as the individual scores were not available. The factors of the trait, method, and MM correlation matrices and the core matrix were interpreted, and compared with Fiske's results.

Hohn, M. E. (1979). Principal component analysis of three-way tables. Journal of the International Association of Mathematical Geology, 11, 611-626.

A concise, straightforward description of T3 based on Tucker (1966). Illustrated with geological data: 4 localities of sample collection from the Early Jurassic scales of the Paris Basin, 3 fractions of the organic extracts and 6 organic elements or elemental ratio's. Data standardized by elements. Varimax rotation for all components. Neat solutions. Uses 'classical' score matrices based on combinationmodes for interpretation.

Hohn, M. E. \& Friberg, L. M. (1979). A generalized principal components model in petrology. Lithos, 12, 317-324.

An exposition of T3 is presented and its usefulness in petrology is explained. The method is illustrated with 4 samples of Machas charnockites of which 9 eations and 1 ratio were determined from 3 minerals. The data were standardized by sample; factor scores on combination-mode components were used. A second example 
comprises a set of data from the Spuhler Peale Formation in Montana (9 cations, 4 minerals and 3 samples).

Imada, A. S. \& London, M. (1979). Relationships between subjects, scales and stimuli in research on social perception. Perceptual and Motor Skills, 48, 691-697.

Two hundred and sixty college students of varying ethnic backgrounds rated 6 ethnic stimuli on 24 bipolar semantic scales. T3. Varmiax on factors for stimuli and subjects, but not on those for scales. The core matrix was difficult to evaluate.

Inn, A., Hulin, C. L. \& Tucker, L. R. (1972). Three sources of criterion variance: Static dimensionality, dynamic dimensionality and individual dimensionality.

Organizational Behavior and Human Performance, 8, 58-83.

Eleven performance measures were collected from 184 airline reservation agents for each of 5 consecutive months. Discussion of input scaling. Detailed analysis of solution (time-mode components are overall level, trend, 'acceleration'). 'Idealized subjects' were used to characterize the subject dimensions. The computations for and the results of this procedure are shown in great numerical detail.

Israelsson, A. (1969). Three-way (or second order) component analysis. In H. Wold \& E. Lyttkens (eds), Nonlinear iterative partial least-squares (NIPALS) estimation procedures. Bulletin of the International Statistical Institute, 43, 29-51.

Proposal of T2, and a short discussion of its estimation within the NIPALS framework.

Jaffrennou, P. A. (1978). Sur l'analyse des familles finies de variables vectorielles. Bases algèbriques et application à la description statistique. Pre-publication No. 4. Départment de Mathématiques, University of Saint-Etienne, France.

Jennrich, R. (1972). A generalization of the multidimensional scaling model of Carrol \& Chang. UCLA Working Papers in Phonetics, 22, 45-47.

Proposal to relax assumptions of INDSCAL to allow for individual positioning of the common space axes (= IDIOSCAL). Very brief sections on estimation and computing.

Karnas, G. (1975). Note sur une procédure d'analyse de données relatives à une correspondance ternaire ou pseudo-ternaire par la méthode d'analyse binaire de Faverge. Le Travail Humain, 38, 287-300.

Proposal to string out a three-mode matrix in one of three ways in order to perform on the resultant (two-mode) matrix a variant of the singular value decomposition (called the binary method of Faverge). One of the stringing-out proposals is identical to forming a combination-mode (Tucker, 1966). The other two are variants of the same idea. Illustrated with beer appreciation data, and data of tram conductors judging aspects of their profession.

Kjerulff, K. \& Wiggins, N. H. (1976). Graduate student styles for eoping with stressful situations. Journal of Educational Psychology, 68, 247-254.

Thirty-four graduate students were asked to rate 26 stressful situations encountered since entering graduate school on 11 characteristics. Data centred by subtracting the grand mean for each rating scale. T3 was applied with varimax rotation for situations, scales and the two subject dimensions. Reasonable amount of detail presented. Validation with outside variables.

Knobloch, E. M. (1972). Einschätzung von leistungsrelevanten Begriffen. Unpublished masters thesis, University of Hamburg.

Kohler, A. (in preparation). Das Trimod-Programm-System (TRIPSY) zur

Berechnung der dreimodalen Faktorenanalyse nach Orlik.

Description of a computer program implementing Orlik's (1980) Summax model. 
Kouwer, B. J. (1967). Driemodale factoranalyse. Programmabeschrijving (GRON. PSYCH. 07+07BIS). Orthogonale rotaties (GRON.PSYCH.12). Reports, Institute of Psychology, University of Groningen, The Netherlands.

Kroonenberg, P. M. (1981 a). User's guide to TUCKALS3. A program for three-mode principal component analysis. WEP-reeks, WR 81-6-RP, Vakgroep WEP,

University of Leiden, The Netherlands, [1979].

A description of the implementation of the algorithm described in Kroonenberg \& De Leeuw (1980). Includes a detailed example from Dutch politics.

Kroonenberg, P. M. (1981b). Scaling of input data for three-mode principal component analysis. WEP-reeks, WR 81-21-EX, Vakgroep WEP, University of Leiden, The Netherlands.

A number of proposals for scaling of input data are collected within one framework. Examples of some of the more common scaling procedures are given, and some effects on three-mode component analysis are considered.

Kroonenberg, P. M. (1981c). User's guide to TUCKALS2. A program for three-mode principal component analysis with extended core matrix. WEP-reeks, WR 8135-RP, Vakgroep WEP, University of Leiden, The Netherlands.

Description of the implementation of the algorithm described in Kroonenberg \& De Leeuw $(1977,1978)$. Includes an example from the Dutch political scene.

Kroonenberg, P. M. \& De Leeuw, J. (1977). TUCKALS2: A principal component analysis of three-mode data. Res. Bull. RB. 001-77, Department of Data Theory, University of Leiden, The Netherlands.

An ALS method to estimate T2 is presented, in which the principle components are computed for two of the three modes, resulting in an extended core matrix. Two examples from the 1968 Dutch political scene, i.e. 11 psychologists indicating which of 12 parties had which of 17 aspects, and 100 psychology students rating the similarity on a rating scale of the nine major Dutch parties. A method for producing joint plots of two modes is introduced, as well as an algorithm for orthonormally rotating an extended core matrix.

Kroonenberg, P. M. \& De Leeuw, J. (1978). TUCKALS2: Een hoofdassenanalyse voor drieweggegevens. Methoden en Data Nieuwsbrief (vd SWS vd VVS), 3 (3), 30 53.

A condensed (Dutch) version of Kroonenberg \& De Leeuw (1977).

Kroonenberg, P. M. \& De Leeuw, J. (1980). Principal component analysis of threemode data by means of alternating least squares algorithms. Psychometrika, 45, 69 97.

A new method to estimate T3 is discussed, and the convergence properties of the ALS algorithm are considered. A special case of T3, using an extended core matrix, i.e. T2 (which was treated extensively in Kroonenberg \& De Leeuw, 1977), is outlined as well. The Miller \& Nicely data on the confusion of English consonants (16 consonant spoken, 16 consonants heard and 17 degrading conditions of the spoken sound) are used as illustration. Very clear interpretable solutions and core matrices. Contains illustrations of rotation of T2 core matrix to diagonality simultaneous for all frontal planes, and of joint plots of the components of two modes.

Lammers, C. J. (1974). Groei en ontwikkeling van de ziekenhuisorganisaties in Nederland. Interimrapport, Institute of Sociology, University of Leiden, The Netherlands.

To assess the growth of the organizational structure of 188 Dutch hospitals, data on 27 variables were collected over 11 years. The T3 analysis is discussed and 
presented in great detail. The results are related to the average values of the variables over time.

Lastovicka, J. L. (1981). The extension of component analysis to four-mode matrices. Psychometrika, 46, 47-57.

L. presents the direct generalization of Tucker's (1966) model to four-mode data. The computational procedure is the direct analogue of Tucker's Method I. The illustration is taken from advertising ( 27 subjects, 5 exposure occasions, 6 advertisements, 16 items). All component matrices were varimax rotated.

Law, H. G. \& Snyder, Jr, C. W. (1979). Three-mode models for the analysis of psychological data. Australian Psychologist, 14, 214. (conference abstract).

The paper gives a non-technical overview of recently developed three-mode techniques for the analysis of psychological data: T3, Harshman's PARAFAC, INDSCAL, ALSCAL, PINDIS, a version of Analysis of Covariance Structures. The techniques are discussed with reference to simple examples.

Law, H. G. \& Snyder Jr, C. W. (1981). An introduction to the analysis of covariance structures: A general model for data analysis. In J. M. Morris (ed.), Proceedings of a Seminar on Measuring Social Behaviour in Road Research. pp. 49-60. Vermont South, Victoria: Australian Road Research Board.

A general approach to the analysis of covariance structures is shown to include Tucker's (1966) common factor model as well.

Leah, J. A., Law, H. G. \& Snyder Jr, C. W. (1979). The structure of self-reported difficulty in assertiveness: An application of three-mode common factor analysis. Multivariate Behavioral Research 14, 443-462.

T3 used in the development of assertiveness inventory of 56 items (considered as a completely crossed two-facet design of 7 referents and 8 response classes). Used on two samples of 140 and 130 subjects respectively. Varimax transformation of first sample used on second sample to test congruence. High overall and detailed agreement between the structures of the two samples. Uses Tucker's (1966) Method III.

Leichner, R. (1975). Zur Verarbeitung psychiatrischer Information. I. Diagnostica, 21, $147-166$.

Five psychiatrists judged 15 patients (schizophrenics, cyclothymics and neurotics) on a semantic differential scale of 21 bipolar items on 3 occasions in a carefully designed study. T3 was applied for each occasion and the (only partially presented) results were compared with interesting results. Some discussion on standardization of the data. Cursory examination of the core matrix.

Levin, J. (1963). Three-mode factor analysis. Unpublished doctoral thesis, University of Illinois. (Dissertation Abstracts International, 1964, 24 (12), 5530-5531) (see Levin, $1965)$

Levin, J. (1965). Three-mode factor analysis. Psychological Bulletin, 64, 442-452.

A medium-level explanation of T3 via generalization of the singular value decomposition of two-mode matrices. T3 illustrated with 2 data sets. Semantic differential data (31 widely differering concepts rated on 20 scales by 60 subjects) analysed with Tucker's (1966) Method I or II. Stimulus-Response Inventory of Anxiousness data (14 responses, 11 situations, 169 subjects) were analysed using Method III (Tucker, 1966). Detailed numerical results.

Lilly, R. S. (1965). A developmental study of the semantic differential. ETS Research Bulletin 65-28; Unpublished doctoral dissertation, Princeton University.

(Dissertation Abstracts International, 1966, 26 (7), 4063-4064).

The same 20 concepts (of various nature) were rated on the same 28 11-point 
adjective scales by $96,110,107$ and 100 parochial school children in grades $3,4,6$ and in high school. Both the adjectives and concepts were high frequency words. Separate T3 analyses were performed for each of the grades. Apparently only the component matrices were interpreted and not the core matrix.

Lingoes, J. C. \& Borg, I. (1978). A direct approach to individual differences scaling using increasingly complex transformations. Psychometrika, 43, 491-520.

A family of models for the representation and assessment of individual differences for two-mode three-way data is embodied in a hierarchically organized and sequentially applied procedure (PINDIS), which uses increasingly complex transformations of some common or hypothesized space. The method is a mixture of simultaneous analysis of the matrices of all 'individuals' and separate analyses on each individual. It allows assessing the appropriateness of models like INDSCAL and three-mode scaling.

Litt, E. N. (1966). A factorial study of responses to abstract paintings. Unpublished masters thesis, University of Illinois.

Lohmöller, J. B. (1978). How longitudinal factor stability, continuity, differentiation, and integration are portrayed into the core matrix of three-mode factor analysis. Paper presented at the European Meeting on Psychometrics and Mathematical Psychology, Uppsala, Sweden, 16 June.

Concepts for the study of change, like stability, continuity, integration, differentiation, and transformation are defined within the framework of a multivariate autoregressive model. How these concepts show up in the parameters of a three-mode factor analysis is investigated by an artificial example, and data from the Augsburg longitudinal study (5 attributes, 4 time periods, and roughly 1900 schoolehildren).

Lohmöller, J. B. (1979a). Die trimodale Faktorenanalyse von Tucker: Skalierungen, Rotationen, andere Modelle. Archiv für Psychologie, 131, 137-166.

L. provides a very comprehensive survey of many aspects of T3, such as the model itself, the relationships between T3 and three-way ANOVA, rotations of factor matrices and core matrix, factor scores, relationships with two-mode FA, scaling of input data, additive versus multiplicative models and types of programs. Most of the concepts are illustrated with data of roughly 1900 school children from the Augsburg longitudinal study ( 3 time periods) of 8 subtests of the primal mental abilities test.

Lohmöller, J. B. (1979b). Programmbeschreibung von FA-3-Trimodale Faktorenanalyse. In J. B. Lohmöller, Das COR-Programm-system zur Korrelationsanalyse.

Fachbereich Pädagogik, Hochschule der Bundeswehr München, Neubiberg, FRG.

As part of a larger system for the analysis of correlation matrices, three programs for T3 are described, which use the three methods of Tucker (1966) respectively.

Lohmöller, J. B. (1981). Stabilität und Kontinuität in Längschnittdaten, analysiert durch T- und trimodale Faktorenanalyse. Technical Report. Fachbereich Pädagogik, Hochschule der Bundeswehr München, Neubiberg, FRG.

Lohmöller, J. B. \& Oerter, R. (eds) (1979). Medien in der Erzieherausbildung: Erprobung des Medienverbundes "Vorschulische Erziehung im Ausland". München: Oldenbourg Verlag.

Eight hundred subjects judged 8 media packages on 27 rating scales. The scale components were varimax rotated, and the core matrix was symmetrically rotated. Factor scores for the subjects were computed. The means were analysed by threeway ANOVA. The six variable components were introduced in a path analysis model, together with various other variables, such as social and personal background, job-related motivations and attitudes towards learning. 
Lohmöller, J. B. \& Wold, H. (1980). Three-mode path models with latent variables and partial least squares (PLS) parameter estimation. Forschungsbericht 80.03, Fachbereich Pädagogik, Hochschule der Bundeswehr München, Neubiberg, FRG. Presented at European Meeting of the Psychometric Society, Groningen, The Netherlands, June 18-21 [revised 1982].

An exposition of various three-mode models is given, including two new models. One for indicators observed both over time and cases, one for three-mode path analysis with latent variables. Includes algorithm for three-mode factor and path analysis within PLS (or ALS) context. Example: three-mode path analysis for 8 school subjects measured on 6 occasions. Correlation matrices from 2500 children.

London, M., Crandall, R. \& Fitzgibbons, D. (1977). The psychological structure of leisure: Activities, needs, people. Journal of Leisure Research, 9, 252-263.

For 83 students the presence of 15 need-satisfying attributes was measured with a seven-point rating scale for 30 leisure activities. The stability of the T3 solution was checked by split-half analysis. Discussion of the presented results of the factor loading and core matrices.

Love, W. D. \& Tucker, L. R. (1970). A three-mode factor analysis of serial learning. Report of the Office of Naval Research.

Variations in serial position learning curves over 10 stages of learning and 33 individuals using 19 trials were studied by means of T3 analysis for a list of 20 CVC trigrams. Moderately detailed analysis and interpretation.

MacCallum, R. C. (1974a). A comparison of two individual differences models for multidimensional scaling: Carroll \& Chang's INDSCAL and Tucker's three-mode factor analysis. Unpublished doctoral thesis, University of Illinois. (Dissertation Abstracts International, 1975, 35 (7-B), 3619). (See MacCallum, 1976a, 1976b.)

MacCallum, R. C. (1974b). Relations between factor analysis and multidimensional scaling. Psychological Bulletin, 81, 505-516.

Treats the differences between factor analysis and scaling in general. Discusses briefly the relations between INDSCAL and Tucker's three-mode scaling.

MacCallum, R. C. (1976a). Effects on INDSCAL of non-orthogonal perceptions of object space dimensions. Psychometrika, 41, 177-188.

Investigation into the effect of violations of assumptions of the INDSCAL model. Relation between INDSCAL and Tucker $(1972 a)$ model is discussed; the latter is recommended when violation of assumptions in the former are suspected.

MacCallum, R. C. (1976b). Transformation of a three-mode multidimensional sealing solution to INDSCAL form. Psychometrika, 41, 385-400.

Relations between Tucker $(1972 a)$ and INDSCAL are discussed. A gradient procedure is developed which seeks to diagonalize the core matrix in all its frontal planes. A necessary condition for the extended core matrix to be diagonal is that the core matrix is diagonal. The developed procedure can be seen as a first step towards checking the assumptions of the INDSCAL model, as the latter is defined to have a diagonal extended core matrix. It is also shown that a core matrix consisting of two frontal planes can always be diagonalized. The transformation procedure is applied to the Tucker $(1972 a)$ data, and to the Jones \& Young data consisting of judgements of 19 respondents about the similarities of 17 stimulus persons (see also De Leeuw \& Pruzansky, 1978).

McCloskey, J. \& Jackson, P. R. (1979). THREE-MODE: A FORTRAN IV program for three-mode factor analysis. Behavior Research Methods \& Instrumentation, 11, $75-76$.

A computer program for T3 (Tucker, 1966-Method I) is described without technical details. 
Meijs, B. W. G. Ph. (1980). Huis van bewaring en subkultuur: Een empirische studie bij jeugdige gedetineerden naar het effekt van '102 dagen' preventieve hechtenis op attitudes en andere indikatoren van subkultuur. Unpublished masters thesis, University of Leiden, The Netherlands.

T3 (as implemented by Kroonenberg \& De Leeuw, 1980) was one of the analyses of semantic differential data from 37 juvenile delinquents judging their surroundings, i.e. remand prison, home, law enforcers, and the judiciary (26 aspects, 10 scales). The data were collected at two times (directly after intake and one month later), and each time was analysed separately. Interesting shifts of opinions about aspects could be observed.

Meuwese, W. (1970). Een vergelijking van twee methoden van beoordeling van verbale stimuli. Nederlands Tijdschrift voor de Psychologie, 25, 594603.

A selection of 15 university subjects were judged by 44 staff and students of a technical university on 21 seven-point rating scales. T3 was performed, and all modes were interpreted but not the core matrix. The stimulus space was compared with a MDS solution obtained from paired comparison data.

Mills, D. H. \& Tucker, L. R. (1966). A three-mode factor analysis of clinical judgment of schizophrenicity. Journal of Clinical Psychology, 22, 136-139.

Schizophrenicity judgements of 23 persons (patients and normals) on 20 items of the WAIS vocabulary and comprehension by 5 judges was subjected to T3. A nice, clearly interpretable solution appeared.

Montanelli, D. S. (1972). Multiple-cue learning in children. Developmental Psychology. 7, 302-312.

Response patterns of 144 children in a multiple-cue learning experiment with 8 trial blocks and 3 cue weightings were analysed by T3 (or actually T2, as no components were determined for the cue weightings). Very little numerical information was presented and only a cursory interpretation given.

Moonen, J. (1978). Computergestuurd Onderwijs. Een onderzoek naar de mogelijkheden tot geïntegreerd gebruik van een computergestuurd systeem in een statistiekkurrikulum. Doctoral thesis, Leiden, The Netherlands.

As part of a large scale investigation into the possibilities of integrating computer aided instruction into a statistics course, the data of 121 subjects rating 8 organizational approaches to studying statistics on 8 aspects related to a statistics course were analysed using TUCKALS2 (Kroonenberg \& De Leeuw, 1977, 1980; Kroonenberg, 1981c). The data were collected and analysed twice, once after one third of the course was over, and once at the end of the course. Rather straightforward interpretation; no interpretation was attempted of the subjects.

Muthén, B., Olsson, U., Pettersson, T. \& Stahlberg, G. (1977). Measuring religious attitudes using the semantic differential technique: An application of three-mode factor analysis. Journal for the Scientific Study of Religion, 16, 275-288.

120 theology students were presented with 6 religious concepts to be seored on 60 semantic bipolar seven-point scales. These data were subjected to T3. A straightforward application and interpretation.

Orlik, P. (1980). Das Summax-Modell der dreimodalen Faktorenanalyse mit interpretierbarer Kernmatrix. Technical Report, University of Saarland, Saarbrücken, FRG. [1976].

O. proposes a completely symmetric three-mode model (called Summax) with a three-mode identity matrix. The appearance of the model is identical to that of Carroll \& Chang (1970), however, the 'factor' loadings are determined in a different way. A leading-sign pattern matrix is sought for each of the modes such that the 
sum of all elements with their 'best' leading-sign is maximal. From these pattern matrices for the data matrix the 'factor' loadings are derived. If these 'loading' matrices are rotated, the counter-rotated core matrix will contain the direction cosines of the derived 'factors'. Illustrated by an experiment in which 4 coloured disks are judged on 10 rating scales by 8 subjects.

Redfield, J. (1978). TMFA: A FORTRAN program for three-mode factor-analysis and individual-differences in multidimensional-scaling. Educational and Psychological Measurement, 38, 793-795.

Description of a program to perform all three methods of Tucker (1966) and also three-mode scaling (Tucker, 1972a); includes fitting of the additive constant in case of input of similarities. Large number of options for input, analysis and output.

Redfield, J. \& Stone, A. (1979). Individual view points of stressful life events.

Journal of Consulting and Clinical Psychology, 47, 147-154.

Eighty-five students rated 44 stressful life events on six 21 interval bipolar scales. Analysis with T3. The event and scale factors were graphically rotated to simple structure. The 3 student factors by varimax. The factors were scaled according to Snyder \& Wiggins (1970). Little numerical detail. Validation with outside variables.

Rösler, F. (1972). Dimensionen der Aktivitäten und deren Beziehungen zu den Persönlichkeitsfaktoren 'Extraversion/Introversion' und 'Neurotizismus' sensu Eysenk. Unpublished masters thesis, University of Hamburg (see Rösler, 1975).

Rösler, F. (1975). Die Abhängigkeit des Elektroenzephalogramms von den Persönlichkeitdimensionen E und N sensu Eysenk und unterschiedlich aktivierenden Situationen. Zeitschrift für Experimentelle und Angewandte Psychologie, 22, 630-667.

As part of a larger study a reduction of frequency spectra was obtained via T3 on the data of 32 subjects, 18 measuring periods, and 40 frequencies. However, only principal components was performed on the frequencies mode. The factors were scaled as suggested by Bartussek (1973).

Rösler, F. (1979). Identifying interindividual judgement differences: INDSCAL or three-mode factor analysis. Multivariate Behavioral Research, 14, 145-167.

Seventy subjects judged 9 German key-politicians on 22 bipolar seven-point attribute scales. The proximity matrices from the computed profile similarities were analysed with INDSCAL. T3 was applied to the original data. The results suggested that T3 was more appropriate to describe the interindividual judgement differences when correlated with external variables.

Rowe, H. A. H. (1979). Three-mode factor analysis: Problems of interpretation and possible solutions. Australian Psychologist, 14, 222-223. Abstract of paper presented at the 14th Annual Conference of the Australian Psychological Society, University of Tasmania, 30 August.

A summary of applications with T3 is presented. An example (18 problem solving strategies on 12 tasks of varying content and difficulty by 89 subjects) is discussed on a conceptual level; no numerical details are given. Special attention is given to meaningful interpretations of the core matrix in relation to different types of standardizations of the raw data. Reification with external variables.

Rychlak, J. F., Flynn, E. J. \& Burger, G. (1979). Affection and evaluation as logical processes of meaningfulness independent of associative frequency. Journal of General Psychology, 100, 143-157.

Forty-three undergraduates rated $25 \mathrm{CVC}$-trigrams and 25 words and paralogs according to 7 different instructions. The trigrams and the words-paralogs were 
analysed separately with T3. Only the instructions were interpreted in both cases, as only one factor was present in the verbal materials and the subjects matrix suggested the presence of only one factor. Because of the decision to retain only one factor for subjects and word materials, it was decided not to carry out a 'core matrix' analysis.

Saile, H. (1979). Zur Struktur der Einschätzung von Lebensereignissen. Eine Untersuching über Beurteilungsunterschiede mittels dreimodaler Faktorenanalyse. Unpublished masters thesis, University of Trier.

Partially reported in Gräser et al., 1981.

Sands, R. (1978). Component models for three-way data: ALSCOMP3, an alternating least squares algorithm with optimal scaling features. Unpublished masters thesis, Department of Psychology, University of North Carolina. (See Sands \& Young, 1980).

Sands, R. \& Young, F. W. (1980). Component models for three-way data: ALSCOMP3, an alternative least squares algorithm with optimal scaling features. Psychometrika, 45, 3967 [1978].

An alternating least squares (ALS) method is proposed for the weighted Euclidean (a three-mode three-way generalization of the two-mode three-way INDSCAL model) and for the replicated PCA model, where 'subjects' in the third mode are treated as replications. The data may be defined at various measurement levels with various measurement characteristics. It is the only three-mode method which allows for other than metric data. Compared with the other ALS methods (Lohmöller \& Wold, 1980; Kroonenberg \& De Leeuw, 1980) the treated models are somewhat less general. Illustrated with a Monte Carlo study, and data on perception of political figures and roles.

Schmitt, N., Coyle, B. W. \& Saari, B. B. (1977). A review and critique of analyses of multitrait-multimethod matrices. Multivariate Behavioral Research, 12, 447-478.

T3 (Method III) is discussed as one of the techniques appropriate for multitraitmultimethod matrices. A small example constructed from the data of 310 persons being rated on 7 triats by 4 raters is used as illustration. The unrotated core matrix is nicely diagonal.

Shikiar, R. (1974a). The perception of politicians and political issues: A multidimensional sealing approach. Multivariate Behavioral Research, 9, 461-477.

Similarity judgements among all possible pairs of the 8 candidates for the 1972 presidency election (USA), among the 12 attributes, and among all candidateattribute combinations were analysed using Tucker $(1972 a)$. The components were validated by regression analyses using additional variables.

Shikiar, R. (1974b). An empirical comparison of two individual differences multidimensional scaling models. Educational and Psychological Measurement, 34, 823-828.

For each of five similarity judgement tasks (8-20 stimuli; 115 (student) judges), the INDSCAL and three-mode scaling object space solutions were compared, and found to be very similar. The comparisons of the subject spaces were less similar for largely unexplained reasons.

Sjöberg, L. (1977). Choice frequency and similarity. Scandinavian Journal of Psychology, 18, 103-115.

T3 (Tucker, 1966, Method III) was used to analyse the judgements of 215 students about 7 Swedish political parties using 18 rating scales. The judgements were made as part of a larger study. The three component spaces for the scales and the parties were each varimax rotated, the latter yielding an (unrecognized?) three-dimensional 'horse shoe'. 
Snyder, Jr, C. W. (1970). Intrinsic individual differences in disjunctive conceptual behaviour: Three-mode factor analysis. Unpublished doctoral thesis, University of Pennsylvania. (Dissertation Abstracts International, 1970, 32 (1-B), 544.)

Snyder Jr, C. W. (1976). Multivariate analysis of intrinsic individual differences in disjunctive conceptual behaviour. Multivariate Behavioral Research, 11, 195-216.

T3 with multitrait- multimethod matrix (Tucker, 1966, Method III) with learning data (40 subjects, 10 trial blocks, and 4 response measures). Relatively clear core matrix.

Snyder Jr, C. W. \& Law, H. G. (1979). Three-mode common factor analysis:

Procedure and computer programs. Multivariate Behavioral Research, 14, 435-441.

T3 (Method III) is described in step-by-step format for easy comprehension. The procedure described uses the SPSS package, subprogam FACTOR, interfaced with specialized programs written by the authors.

Snyder Jr, C. W., Law, H. G. \& Pamment, P. R. (1979). Calculation of Tucker's three-mode common factor analysis. Behavior Research Methods \&

Instrumentation, 11, 609-611.

The working of three programs is described. They were written to interface with the SPSS FACTOR routine to ealculate a solution for T3 by Tucker's Method III (1966).

Snyder Jr, C. W. \& Law, H. G. (1981). Three-mode models for road research. In J. M. Morris (ed.), pp. 39 48. Proceedings of a Seminar on Measuring Social Behaviour in Road Research. Vermont South, Victoria: Australian Road Research Board.

Factor-analytic and multidimensional scaling models which can be used on threeway data sets are reviewed in terms of their usefulness for road researchers.

These models include Harshman's PARAFAC, Tucker's three-mode common factor analysis, Carroll \& Chang's INDSCAL, and Takane, Young \& De Leeuw's

ALSCAL. Enough of the formalities associated with each model is presented to clarify the particular approach to data analysis. The results are characterized in terms of a hypothetical road research project on traffic noise.

Snyder, F. W. (1967). An investigation of the invariance of the semantic differential across the subject mode. Unpublished masters thesis, University of Illinois.

A reanalysis with T3 of Osgood's Thesaurus data revealed the possibility of two subject factors.

Snyder, F. W. (1968). A unique variance model for three-mode factor analysis.

Department of Psychology, University of Illinois (also doctoral thesis, 1969).

(Dissertation Abstracts Intrnational, 1969, 30 (3-B), 1349).

A 'true' T3 factor model is presented which allows for unique variances for two of the modes and for their combinations. It extends the model presented in Tucker (1966). The model is a precursor of Bentler \& Lee's (1979) model. The computational procedure seems complex and cumbersome. Two illustrations: (1) 40 measures on 3 different sets of administrative tasks for 232 school administrators;

(2) in each of 6 semesters 18 character and work traits of 222 students of an aviation school were rated by their teachers. Detailed numerical results.

Snyder, F. W. \& Tucker, L. R. (1970). On the interpretation of the core matrix in three-mode factor analysis. Paper read at the Psychometric Society Meeting, March.

Snyder, F. W. \& Wiggins, N. (1970). Affective meaning systems: A multivariate approach. Multivariate Behavioral Research, 5, 453-468. [1968].

T3 was applied to the semantic differential ratings of 20 comcepts by 100 subjects on 76 bipolar adjectival scales. The 4 scale and 5 concept factors were varimax rotated, the concept dimensions were given somewhat questionable names, 
and the subject dimensions were rotated by hand. An interpretation was attempted of the rather jumbled core matrix.

SOUPAC program descriptions. (1973). Computing Services Offices, University of Illinois.

Describes implementations of Tucker's (1966) methods I and II for three-mode factor analysis.

Stewart, T. R. (1971). The relation between three-mode factor analysis and multidimensional scaling of personality trait profiles. Unpublished doctoral thesis, University of Illinois. (Dissertation Abstracts International, 1971, 32 (2-B), 1197.) (see Stewart, 1974).

Stewart, T. R. (1974). Generality of multidimensional representations. Multivariate Behavioral Research, 9, 507-519.

Proposes comparing the MDS solution of combination-mode similarity matrices (15 personality descriptions judged in pairs by 98 subjects), and a $\mathrm{PCA}$ solution of a combination-mode three-mode matrix (judgements on 4 rating scales of 81 hypothetical people by the same 98 subjects) in search for 'generality' of the multidimensional configuration. Although it claims to use Tucker (1972a) for the MDS, only the combination-mode aspect of it is used.

Stoop, I. (1980). Sekundaire analyse van de "Van jaar tot jaar data" met behulp van niet-lineaire multivariate technieken: Verschillen in de schoolloopbaan van meisjes en jongens. Research Bulletin, RB 001-80, Department of Data Theory, University of Leiden, Leiden, The Netherlands.

As part of a reanalysis of the data from a longitudinal study of the school and vocational career of Dutch children, TUCKALS2 (Kroonenberg \& De Leeuw, 1977, 1980; Kroonenberg, 1981c) was applied. Also the merits of the technique in relation to INDSCAL, and some problems with the preliminary version of the program were discussed. The data consisted of correlation matrices (boys and girls) based on 26 variables in the first analysis and of 7 correlation matrices (one for each occupational class of the father) based on the same 26 variables.

Teufel, S. (1969). TUCK, Tuckers Modell einer drei-dimensionalen Faktorenanalyse. Ein FORTRAN IV-Programm. In F. Gebhardt, Statistische Programme des DRZ Teil B: Einzelbeschreibungen. Darmstadt: Programm Information PI-33 des

Deutschen Rechenzentrum.

Triandis, H. C. (ed.) (1972). The Analysis of Subjective Culture. New York: WileyInterscience.

Contains a summary of an unpublished study by Triandis et al. (1967) on interpersonal attitudes (pp. 49,50), and a completely non-technical and nonnumerical, detailed description of a comparative T3 analysis of subjective culture, pp. 299-335).

Triandis, H. C. (ed.) (1976). Variations in Black and White Perceptions of the Social Environment. Urbana, IL: University of Illinois Press.

In chapter 5 an overview is given of the methods of data collection and analysis which are the basis of the other chapters. As an example, a three-mode analysis of 20 behavioural item scales, 104 role pairs, 89 individuals based on cross-products matrices is included. Oblique factor rotations with counter-rotation of core matrix.

Triandis, H. C. (1977). Subjective culture and interpersonal relations across cultures. Annals of the New York Academy of Sciences, 285, $418-434$.

Triandis, H. C., Feldman, J. M., Weldon, D. E. \& Harvey, W. M. (1975). Ecosystem distrust and the hard-to-employ. Journal of Applied Psychology, 60, 44-56.

T3 was used as one of the analyses in a large scale project. It was employed to 
examine a concepts $\times$ judgements $\times$ subjects matrix. The precise dimensions are not given. The results are only partially presented, and the effectiveness of the method for the data is difficult to assess or check.

Triandis, H. C., Tucker, L. R., Koo, P. \& Stewart, T. (1967). Three-mode factor analysis of the behavioral component of interpersonal attitudes. Technical Report No. 50, Department of Psychology, University of Illinois.

Two hundered and fifty subjects from Japan, India and USA responded to semantic and behavioural differential scales. The interpersonal attitudes of the subjects were assessed with respect to stimulus persons varying in sex, age, occupation, and religion. In part reported in H. C. Triandis (1972, pp. 49-50).

Tucker, L. R. (1963). Implications of factor analysis of three-way matrices for measurement of change. In C. W. Harris (ed.), Problems in Measuring Change, pp. 122-137. Madison: University of Wisconsin Press.

The first introduction in the literature of T3. The main principles are presented, and some computational problems are discussed. The missing details appear in later papers (Tucker, 1964, 1966; Levin, 1965); illustrated with an artificial example.

Tucker, L. R. (1964). The extension of factor analysis to three-dimensional matrices. In H. Gullikson \& N. Frederiksen (eds), Contributions to Mathematical Psychology, pp. 110-119. New York: Holt, Rinehart \& Winston.

A more detailed discussion of T3 than Tucker's (1963) paper, but the mathematics is still somewhat awkward. The transformational freedom in the model is also treated in more details. The same artificial example is used as in 1963.

Tucker, L. R. (1965). Experiments in multimode factor analysis. In A. Anastasi (ed.), Testing Problems in Perspective. Washington, DC: American Council on Education. Reprinted from: Proceedings of the 1964 Invitational Conference on Testing Problems, pp. 46-57. Princeton, NJ: Educational Testing Service, 1965.

Presents a very global description of T3. Illustrated by analyses presented in detail in Hoffman \& Tucker (1964), Tucker (1967), and Levin (1965).

Tucker, L. R. (1966). Some mathematical notes on three-mode factor analysis. Psychometrika, 31, 279311.

The basic paper on T3 which presents a detailed and mathematically coherent description of the model. Also a full discussion on the freedom of rotation is given. it contains an outline of the notation which is used by many later authors, and introduces some new terminology. Three computational methods are presented, the first two more in the spirit of principal component analysis rather than factor analysis. Method I is a straightforward application of the basic formulae. Method II and III are applicable to the analysis of data with one (very) large mode.

Method III is particularly appropriate for 'multitrait-multimethod' type matrices. An extension of the general method is described in which allowance is made for unique variances for each combination variable. This model uses a version of Method III for the analysis. A fictitious body of data is used to illustrate several points.

Tucker, L. R. (1967). Three-mode factor analysis of Parker-Fleishman complex tracking behavior data. Multivariate Behavioral Research, 2, 139-151.

T3 was used to analyse data from a simulation of tracking during airborne radar intercept missisons (4 accuracy measures, 10 stages of practices and 203 individuals). In particular the available multimeasures multistage method matrix of correlations with estimated communalities was used with Tucker's Method III $(1966 b)$. Extensive information on and interpretation of the solution. 
Tucker, L. R. (1972a). Relations between multidimensional scaling and three-mode factor analysis. Psychometrika, 37, 3-27.

The multidimensional scaling variant of T3 presented, which later came to be called 'three-mode scaling', assumes that the first two modes are equal, and that the input consists of a scalar-product matrix for each of subjects. This results in an object space, a person space and a core matrix, of which the frontal planes contain the subject components' weights for the components of the common object space as well as their angles between those dimensions. Also the extended core matrix is introduced as an aid for interpretation. Some special transformations of the core matrix are suggested. The technique is illustrated with data from an adjective similarity study (all 66 pairs from 12 adjectives were judged as to their similarity by 87 students). The adjectives were designed to form a circle, which indeed was found, but not properly recognized. The interpretation of the core matrix and person space was made by using 'conceptual' individuals.

Tucker, L. R. (1972b). Use of three-mode factor analysis in MDS. Paper presented as the Workshop on Multidimensional Scaling, University of Illinois, 7-10 June, 1972.

Summary presentation of theory in Tucker (1972a). Illustrations from Helm's colour data and Wish' relations-between-nations data.

Tucker, L. R. (1975). Three-mode factor analysis applied to multidimensional scaling. Paper presented to the US-Japan Seminar on Theory, Methods, and Applications on Multidimensional Scaling and Related Techniques, La Jolla, CA, 20-24 August.

A concise overview of three-mode factor analysis, the T2 model, three-mode scaling. Illustrated with artificial data.

Tucker, L. R. \& Messick, S. (1963). An individual differences model for multidimensional scaling. Psychometrika, 28, 333-367.

The point-of-view approach to the analysis of individual differences for dissimilarity data (a forerunner of T2/T3) is developed. The subjects are factored to construct 'idealized individuals' representing different points-of-view. The coordinates of the 'idealized individuals' in the subject space are used to construct estimated distances of all stimulus-pairs for each of the idealized individuals. Separate MDS analyses are performed to obtain separate stimulus spaces for each 'point-of-view'. Illustrated with political judgement data.

Tzeng, O. C. S. (1972). Differentiation of affective and denotative meaning systems in personality ratings via three-mode factor analysis. Unpublished doctoral thesis,

University of Illinois. (Dissertation Abstracts International, 1973, 34 (2-B), 864) (see Tzeng, 1975, 1977a).

Tzeng, O. C. S. (1975). Differentiation of affective and denotative meaning systems and their influence in personality ratings. Journal of Personality and Social Psychology, 32, $978-988$.

Fifty Belgian males scored 40 person concepts on 40 semantic scales to investigate person perception. Component analysis loadings from T3 were rotated by a complex scheme on so-called marker scales of the EPA dimensions and on non-marker scales with the object to separate the affective from the denotative semantic space. In conjunction with the core matrix three subject components were interpreted.

Tzeng. O. C. S. (1977a). Differentiation of affective and denotative semantic subspaces. Annals of the New York Academy of Sciences, 285, 476-500.

In each of four countries $80-160$ subjects scored $24-42$ concepts on $40-60$ semantic differential scales. The scales were separated in marker (affective) and non-marker (denotative scales); see Tzeng, 1975. T3 was applied for each country. 
Comparisons between the component matrices and the core matrices of the four countries are given.

Tzeng, O. C. S. (1977b). Individual differences in self-conception: Multivariate approach. Perceptual and Motor Skills, 45, 1119-1124.

Investigation of determinants of the affective and denotative semantic structures in the process of self-conception. T3 applied to semantic differential ratings of 11 ego-related concepts on a representative set of 29 (?) scales from a homogeneous group of 29 male college sophomores. The retained factors (after varimax) were correlated with other variables. Virtually no numerical details.

Tzeng, O. C. S. \& Landis, D. (1978). Three-mode multidimensional scaling with points of view solutions. Multivariate Behavioral Research, 13, 181-213.

A rather hybrid stringing together of multivariate procedures called 'three-mode point of view analysis' (3M-POV). Including in sequence Tucker's (1972a) analysis, hierarchical clustering, averaging over individuals in a cluster to obtain coefficients for an 'idealized individual', computing frontal core planes for these idealized individuals, subjecting these planes to an eigen-decomposition and some additional rotation(s). Illustrated with data from Osgood's cross-cultural research.

Van de Geer, J. P. (1974). Toepassing van drieweg-analyse voor de analyse van multiple tijdreeksen. In C. J. Lammers, Groei en ontwikkeling van de ziekenhuisorganisaties in Nederland. Interim rapport, Institute of Sociology, University of Leiden, The Netherlands.

The application of T3 for the analysis of multivariate time series is illustrated with a mini-example. The data are a subset from a study of the growth of 188 Dutch hospitals over 11 years as measured by 27 variables. The computational procedures are shown step by step to aid the explanation of the technique.

Van de Geer, J. P. (1975). Drieweg komponenten analyse (memo). Department of Data Theory, University of Leiden, The Netherlands.

A detailed and clear discussion of many technical aspects of T3 making extensive use of sums of squares interpretations. Ample discussion of scaling of the input data and the effects of this on the analysis. Description of the use of an interactive APL three-mode program.

Van der Kloot, W. A. \& Kroonenberg, P. M. (1982). Group and individual implicit theories of personality: An application of three-mode principal component analysis. Multivariate Behavioral Research, 17, 471-492.

The data of 60 subjects who rated 31 stimulus persons on 11 personality trait rating scales were analysed with Kroonenberg \& De Leeuw's (1980) method of three-mode principal component analysis. The study showed the advantages of including data of 'artificial subjects', and of partitioning the residual sum of squares (badness of fit) for the elements of each of the modes.

Vavra, T. G. (1972). An application of three-mode factor analysis to product perception. In F. D. Allvine (ed.) Marketing in Motion/Relevance in Marketing, no. 33, pp. 578 583. Chicago: American Marketing Association.

Vavra, T. G. (1973). A three-mode factor analytic investigation into the effectiveness of advertising. Unpublished doctoral thesis, University of Illinois. (Dissertation Abstracts International, 1974, 34 (12-A), 7802).

T3 is used to assess the effectiveness of various types of commercials for specific groups of customers. The problem of interpreting the solution is discussed, and two alternative procedures are shown.

Wainer, H., Gruvaeus, G. \& Blair, M. (1974). TREBIG: A 360/75 FORTRAN program for three-mode factor analysis designed for big data sets. Behavioral Research Methods and Instrumentation, 6, 53-54.

A computational outline of Tucker's (1966) Method II is described. 
Wainer, H., Gruvaeus, G. \& Zill II, N. (1973). Senatorial decision making:

I. Determination of structure. Behavioral Science, 18, 7-19.

A T3 analysis (Tucker's (1966), Method II) of US Senate roll call voting was performed ( 8 issues, 6 years, 132 senators). The entries in the data matrix were the point-biseral correlations of senator's votes on a particular issue in a particular year with the popularity of the roll calls in that set. Varimax rotation.

Introduction of the mixed-modal matrices (MMM), which give the loadings of the variables of one mode on the factors of an other. These MMMs turned out be useful in interpreting the Senator factors. These factors were validated using indices that purport to measure various facets on senatorial voting behaviour.

Walsh, J. A. (1964). An IBM 709 program for factor analyzing three-mode matrices. Educational and Psychological Measurement, 24, 669-773.

Describes a computer program for Tucker's (1966) Method I which needs relative large amounts of storage.

Walsh, J. A. \& Walsh, R. (1976). A revised Fortran program for three-mode factor analysis. Educational and Psychological Measurement, 36, 169-170.

A revision of the Walsh (1964) program. Main improvements are organizational with respect to the program itself.

Walter, J. (1976). Komplexe taaksituaties en hartsnelheidsvariabiliteit in de psychiatrie. Technical Report, Stichting Centrum St-Bavo, Noordwijkerhout, The Netherlands.

During 15 conditions of varying mental stress heart frequencies were measured in three ways from 67 members of the staff and patients of a psychiatric institution. T2 (as implemented by Kroonenberg \& De Leeuw, 1980) was applied to the data of all subjects together and to the data of the staff and those of the patients separately.

Wicker, F. W. (1966). A sealing study of synthetic thinking. ETS Res. Bull. RB-6625. Doctoral thesis, Princeton. (Dissertation Abstracts International, 1966, 27 (6-B), 2173) (see Wicker, 1968).

Wicker, F. W. (1968). Mapping the intersensory regions of perceptual space. American Journal of Psychology, 81, 178-188.

Presents a summary of a T3 analysis (25 semantic scales, 26 tones and colours, 59 subjects) which attempted to map intersensory associations between colour vision and the perception of tones on the basis of similarity and semantic judgements. Details reported in Wicker (1966).

Wiggins, N. \& Blackburn, M. C. (1976). Implicit theories of personality: An individual differences approach. Multivariate Behavioral Research, 11, 267-285.

Twenty rates were described on 20 bipolar personality trait adjectives by 51 raters in an own-control design. Both close friends and complete strangers were judged to assess possible individual differences in personality perception. T3 was applied and the rater dimensions were rotated using binormal oblique rotation, the ratee and trait dimensions by varimax. The resulting dimensions were correlated with a host of other variables. Two subject factors were interpreted using the core matrix.

Witzke, D. B. (1975). Determining developmental changes in Holtzman inkblot techniques factors using three-mode factor analysis. Unpublished doctoral thesis, University of Texas, Austin. (Dissertation Abstracts International, 1975, 36 (5-A), 2727).

Zenisek, T. J. (1978). Three-mode factor analysis via a modification of Tucker's computational method-III. Educational and Psychological Measurement, 38, 787792.

Description of program based on Tucker's (1966) Method III for large data sets. 
Zenisek, T. J. (1980). The measurement of job satisfaction: A three-mode factor analysis. Unpublished doctoral thesis, Ohio State University. (Dissertation Abstracts International, 1980, 41 (1-A), 75).

Eight operational measures, each consisting of 23 common job facets were administered to 304 operatives, clerical and first line managers in four widely dispersed steel fabricating plants in order to replicate current findings in the literature as well as to test the efficacy of three-mode factor analysis as a dataanalytic technique.

\section{Late additions}

Bridgman, R. P., Snyder, Jr, C. W. \& Law, H. G. (1981). Individual differences in conceptual behaviour following manipulated controllability. Personality and Individual Differences, 3, 197-205.

Bus, A. G. \& Kroonenberg, P. M. Reading instruction and learning to read: A longitudinal study. SOL-reeks, SOL/82-08, Department of Education, University of Groningen, The Netherlands. (Submitted for publication.)

Kapteijn, A., Neudecker, H. \& Wansbeek, T. (1982). N-mode component analysis. Technical Report, Netherlands Central Bureau of Statistics, Voorburg, The Netherlands. (Submitted for Publication.)

Kroonenberg, P. M. (1983). Three-mode Principal Component Analysis: Theory and Applications. Leiden: DSWO Press.

Law, H. G., Snyder, Jr, C. W., Hattie, J. \& MeDonald, R. P. (eds) (in press). Research Methods for Multi-mode Data Analysis. New York: Praeger.

Lohmöller, J. B. \& Wold, H. (1982). Pfad- und factorenanalytische Ansätze zur differentiellen Entwicklungsbeschreibungen: Die trimodale Pfadanalyse mit Latenten Variablen. In R. Oerter (ed.), Bericht über die 5. Tagung Entwicklungspsychologie in Augsburg, 21-23 September 1981 (Part 1), pp. 26-43.

Ruch, W. (1980). Gemeinsame Strukturen in Witzbeurteilung und Persönlichkeit. Versuch einer empirischen Integration des Gegenstandsbereiches Witzbeurteilung in die differentielle Psychologie. Unpublished doctoral thesis, University of Graz, Austria.

Ruch, W. (1981). Witzbeurteilung und Persönlichkeit: Ein trimodale Analyse. Zeitschrift für Differentielle und Diagnostische Psychologie, 2, 253-273.

Russel, D. (1982). The causal dimension scale - a measure of how individuals perceive causes. Journal of Personality and Social Psychology, 42, 1137-1145.

Snyder, Jr, C. W., Bridgman, R. P. \& Laws, H. G. (1981). Three-mode factor analysis reference curves for concept identification. Personality and Individual Differences, 2, 265-272.

Tucker, L. R. (1969). Some relations between multi-mode factor analysis and linear models for individual differences in choice, judgement, and performance data. Paper presented at the Psychometric Society Meeting.

Wicker, F. W., Thorelli, I. M., Barron, III, W. L. \& Ponder, M. R. (1981). Relationships among effective and cognitive factors in humor. Journal of Research in Personality, 15, 359-370.

Received 23 February 1982

Requests for reprints should be addressed to Pieter M. Kroonenberg, Vakgroep WEP, Department of Pedagogy, University of Leiden, Schuttersveld 9(k. 507), 2316 XG Leiden, The Netherlands. 